Original Research Paper

\title{
Investigating Effects of Water Conditioning on the Adhesion Properties of Crack Sealant
}

\author{
Ahmed Lamarre, Elham H. Fini and Taher M. Abu-Lebdeh \\ Department of Civil, Architectural and Environmental Engineering, \\ North Carolina A\&T State University, Greensboro, NC, USA
}

Article history

Received: 15-02-2015

Revised: $20-02-2016$

Accepted: 23-02-2016

Corresponding Author: Taher M. Abu-Lebdeh Department of Civil, Architectural and Environmental Engineering, North Carolina A\&T State University, Greensboro, NC, USA Email: taher@ncat.edu

\begin{abstract}
This paper investigates the effect of water exposure on three different crack sealants commonly used in cold, moderate and hot climates. It is hypothesized that water penetrates into the interface between crack sealant and substrates causing progressive adhesion failure and that the rate of failure varies depending on the sealant's surface chemistry as relates to its interaction with water molecules in different environmental conditions. Accordingly, this paper measures the change in sealant's adhesion strength and surface energy before and after water conditioning. To study adhesion strength and its change due to water conditioning, three different types of sealant were tested using Direct Adhesion Tester (DAT). It was found that the adhesion strength of all three crack sealants reduces due to water exposure. In addition, to evaluate the surface properties and water phobicity of each sealant, the contact angle between a droplet of water and sealant surface was measured before and after conditioning at different temperature. The objective of the latter experiment was to determine whether sealants susceptibility to water would vary with pavement surface temperature. To do so, a sessile drop method utilizing FTA-1000 was used to determine the contact angle for each of the aforementioned water-sealant pairs at different temperatures. The results obtained were further used to calculate the work of adhesion at each scenario to be correlated to mechanical adhesion strength measured with DAT.
\end{abstract}

Keywords: Crack Sealant, Surface Energy, Contact Angle, Adhesion, Water Susceptibility

\section{Introduction}

Even though sealants are typically used to insulate cracks and joins and prevent water and debris from entering the underlying structure, studies have shown that sealants have a limited lifespan and need to be replaced whenever they can no longer withstand the stresses builds up at the interface between sealants and substrate (Lanteri, 2003; Petrie, 2006). There are four types of sealant failure including adhesive failure, cohesive failure, substrate failure and failure due to loss of sealant properties (Lanteri, 2003). Sealants are typically used to reduce water infiltration into the joint and to help minimize debris contamination ( $\mathrm{Li}$ et al., 2014). It has been reported that adhesion and cohesion are the two types of sealant failures. Cohesive failure is the failure of the sealant material within itself while adhesive failure occurs at the sealant-concrete interface. Li et al. (2014) develop a method to predict joint sealant failures over the lifetime of a concrete surface. The experiment was done by approximating the slabs movement and adhesive strength between concrete and sealant, by determining the sealant's viscoelastic material properties. Life span and effectiveness of sealants are highly impacted by installation practices; for instance dirt and moisture should be fully removed before installing sealants (Lanteri, 2003); it has been stated that selection of an appropriate sealant should be based on properties such as dynamic movement capability, modulus of elasticity, adhesive strength and elasticity recovery properties (Lanteri, 2003). It has been documented that types of sealants are selected based on 
the extent of crack and joint movements indicating a rubbery sealant should be used whenever there is excessive movement (Panek, 1963). It was shown that non-settling sealants split apart when there is rapid movement. A sealant is a mixture of binder, plasticizers and additives. Many sealants fail due to inaccurate dimensions, excessive movements and increase of depth. It has been stated that a sealant in a crack or joint should be able to be extended or compressed to a value of 50\% of its original dimension (Panek, 1963). In addition, many studies have shown that good sealant adhesion occurs on stainless steel, glass and various alloys of aluminum (Panek, 1963). It has been reported that sealants should be also applied on a clean surface to avoid joint contamination; overall use of a primer with lower modulus in concrete or stone is desirable to avoid premature failure.

Sealants adhesion failure usually occurs due to a combination of multiple factors. The most common reason for sealant failure is excessive crack movement due to thermal expansion and contraction; wind loading, moisture-related movement and differential thermal movement (Warseck, 2003). It has been reported that wide cracks and joint can promote formation of a secondary crack. It has been shown that some causes of sealant failure are related to inadequate or imprecise description of the sealant as relates to elongation and modulus properties.

While the cracking, which is the primary mode of deterioration in asphalt pavement, is inevitable, sealing the cracks can help extend the pavement service life. Even though crack sealing is one of the most cost effective methods to maintain pavement service life, pavements with fatigue and alligator cracking cannot be repaired by crack sealing method (Yetkin et al., 2006). It has been reported that the curing time required for the sealant to harden from a liquid state into a semi-solid is very crucial and impacts sealant long term performance. The curing time overall depends on the diffusion of atmospheric moisture or oxygen into sealant. Sealants vary highly based on their physiochemical properties; it has been reported that certain types of sealants can be toxic during chemical reactions while releasing toxic fumes, heat, or both. Malla and coworkers reported that silicone baaed sealants can resist heat up to $250^{\circ} \mathrm{C}$ and will lose their elasticity at $-120^{\circ} \mathrm{C}$ (Ramesh et al., 2011). Sealants are typically characterized based on their performance properties by determining the elongation, compressibility, tensile strength, modulus of elasticity, tear resistance and fatigue resistance (Petrie, 2006). In addition, it has been reported that considerations such as time of year and temperature, safety, traffic control, crack cleaning and drying should be taken into account for crack sealing to ensure sealant can adequately prevent water from entering underlying structure.

Water exposure can lead to progressive damage in pavement mainly due to its high polarity and permeability of sealant polymers. Moisture degrades the Adhesives, Sealants and Coatings (ASCs) by attacking the adhesion properties at the interface, degrading the properties of the bulk polymer or causing dimensional changes of certain adherents. In addition, moisture changes the properties of a material by reacting chemically with the polymer or transforming its glass transition temperature. Moreover, water lowers sealants' tensile strength and modulus by reducing the attractive forces between molecules (Bert, 2011).

A poorly installed or poorly maintained sealant can be deteriorated by water infiltrating the pavement structure. Sealants are very popular in many countries due to their easy installation and performance. There are three groups of sealants including hot-poured, coldpoured and compression sealants. Hot poured sealants are thermoplastic polymers melted at high temperatures. Cold poured sealants are supplied in a liquid form and require no heating prior to application. Compression sealants are manufactured with a synthetic rubber and are effective only when in compression (Angela et al., 2009). It has been reported that hot and cold poured sealants are the most used in the United States. Some studies state that the hot-poured sealants exhibit significant failure in the form of adhesion loss, cohesion loss and spalling; but exhibit higher tensile and compressive stiffness at subzero temperatures. Angela et al. (2009) studied two joints made from diisocyanate and polyol based sealants and reported that diisocyanate sealant was less flexible at low temperatures than polyol based sealants.

The performance analysis of the sealants is commonly based on their physical and structural properties (Biel and Lee, 1997). A sealant tester developed by Yun and coworkers is used to evaluate the performance of various sealants under different conditions. The test includes the measurements of the change $\mathrm{s}$ in resisting forces due to the various widths of the joints and the performed joint sealant (Yun et al., 2010). The tester operates with two concrete slabs laid horizontally with one slab fixed with a vertical steel wall and the other slab stable along the rail. The joint between the concrete is created by cutting the cement with a saw cutter so the sealant can be poured for testing.

While typical crack sealants life is between 3-5 years, some studies have shown that joint sealant failure occurs at a rate of $50 \%$ in less than 20 years and $95 \%$ within 20 years after installation (White et al., 2011). Some studies have promoted the use of ultraviolet radiation and intermittent water spray to accelerate environmental attack on the sealants, however, such excessive aging 
method should be avoided because they are not typically observed during the service life of sealant; other conditioning methods involve several cyclic strains imposed on specimens while monitoring the changes in its physical and mechanical properties.

It has been reported that premature sealant failure is common in cold urban conditions. Countries such as Canada and United States use the ASTM D3405 for the quality control of crack sealants; according to this specification the sealant shall be capable of being brought to a uniform pouring consistency suitable for completely filling the joints without inclusion of air causing or discontinuities (ASTM D6690, 2001). In addition, sealants performance is evaluated under tension, compression and shear tests while their solidifying and curing rates as well as their tack-free time are measured as other indicators of sealant quality in the laboratory. However, studies show that many sealants that performed successfully in the lab failed prematurely in the field (Masson et al., 1998). Sealant failure commonly occurs when the sealant is either improperly formulated and therefore, does not adhere to the substrate; or there is a weak boundary layer formed initially or during service life leading to failure at the weak boundary (Petrie, 2005).

It has been reported that joints sealants are commonly repaired to achieve weather tightness; and in some cases, they are repaired to reduce sound transmission or prevent passage of air, hot gases, or flames. It should be noted that different joint sealants are used for different areas or conditions. Gail (2003) reported that sealants used for exterior applications should be resistant to Ultraviolet (UV) light, air pollution and have acceptable performance in extreme temperatures. She also reported that sealant for interior applications may be required to resist mildew, cleaning agents, or exposure to aggressive chemicals. In addition, sealants exposed to vehicular traffic must be able to resist abrasion, tearing, puncturing and other forms of damage caused by sharp objects such as stones and debris.

Pavement cracks are commonly filled and sealed with crack sealants; those sealants are sometimes subject to routing, cleaning and heating of crack before the sealant application (Masson and Lacasse, 1999). It has been reported that routing enhances sealant performance but heating cracks with hot air lance can be advantageous only in special case; Masson and Lacasse (1999) investigate the conditions under which the Hot Air Lance (HAL) can be used on the asphalt pavement and reported that high adhesion strength can obtained when the pavement surface is not heated or only minimally preheated $\left(100^{\circ} \mathrm{C}\right)$. In contrast, the low adhesion strength was observed when the pavement surface was overheated (over $\left.100^{\circ} \mathrm{C}\right)$.
Joints and crack sealants are widely used to protect pavement from the infiltration of water. ASTM standard D6690-2005 is the most commonly used standard for hot-pour sealants in North America (Haithem et al., 2008). However, the ASTM standard used does not necessary reflect the field performance of sealants. Several comprehensive studies have reported that a good sealant should have adequate adhesion strength with the pavement, the ability to dissipate tensile stresses in sealant and adequate stiffness to resist the penetration of incompressible materials (Fini and Al-Qadi, 2011; Al-Qadi and Fini, 2010; Al-Qadi et al., 2009; Fini et al., 2006). Accordingly, Fini and Al-Qadi (2011) his group developed a series of performance based tests to characterize sealant bulk and interface properties under dry conditions. They modified existing Superpave testing equipment including Rotational Viscometer, Bending Beam Rheometer and Direct Tension Tester to be sued for crack sealant evaluation (Fini and Al-Qadi, 2011). While aforementioned tests are comprehensive and accompanied by field validations, they do not address sealant water susceptibility as relates to sealant surface properties and interface damage. Considering that most sealant failures are adhesion failures and that water plays a major role deteriorating sealant surface properties and interfacial bond, there is a need for a fundamental test which can evaluate sealant susceptibility to water.

Flows through porous are governed by liquid-liquid and liquid-gas interfacial tensions. The measurements of the pore contact angle are simply done by either direct measurements using a sessile drop experiment, or by indirect measurements such as capillary rise technique and thin-layer wicking technique (Li et al., 2014). Li et al. (2014) showed the importance to measure the contact angle in pore to indicate the pore wetting correctly and avoid misusing improper contact angles for the porous surface case. Their research has shown the difference between contact angles in a pore and on a flat surface.

Determining a contact angle of a small droplet from sessile drop has always been challenging. It has been reported that the most common technique to determine a static contact angle is to measure the height as a function of distance from the apex; then derive a curvature either analytically by fitting a straight line to the slope if the drop at the contact angle or numerically by integrating the LaplaceYoung equation. It has been reported that most techniques becomes inaccurate or impractical for a small contact angle, making a sessile drop difficult to observe in profile. Allen (2003) determined a small contact angle using two techniques. The small slope solution, where the drop is assumed to be isothermal 
so there is no variation in surface tension; and the spherical cap solution where the shape of a sessile drop is assumed to be a spherical cap, are the two technique used for the experiment.

The surface displacement caused by a sessile drop could be very small for stiff solid surfaces; but significantly for highly deformable substances and gels (Pozrikidis, 2013). It has been reported that there is a small change of the contact angle for stiff solid surface; and highly deformable substrates cannot withstand capillary force. Pozrikidis (2013) determined a technique on how to prevent the physical deformation of a state at the contact line due to a sessile drop. They spread the capillary force over a strip with molecular or higher dimensions and used a sealing argument to show that the maximum vertical displacement of the contact angle is in order. In addition, they also used another technique where they argued that plastic stresses developing near the contact line restrain the infinite deformation.

\section{Materials and Experimental Method}

\section{Direct Adhesion Test (DAT)}

Adhesion test is conducted by applying tensile force on sealant-substrate interface. In this test the mold assembly consists of two half-cylinder aluminum of 25 $\mathrm{mm}$ diameter and $12 \mathrm{~mm}$ length.

The assembly has a half cylinder mold, open at the upper part. Prior to pouring the sealant, the assembly is heated to facilitate sealant flow and to ensure a uniform bonding area (Fig. 1). A pre-debonded area was formed using a thin shim in form of a notch at the upper edge of the interface; this shim was placed at one side of the assembly to ensure adhesive failure and pre-define the failure path.

In this study, sealant adhesion strength (peak load before failure) and fracture energy (energy required to break the bond) were measured before (dry) and after water conditioning (wet). Specimens were prepared by heating the sealant at $185^{\circ} \mathrm{C}$ for $30 \mathrm{~min}$. That sealant was slowly poured into adhesion molds to avoid trapping air bubble. After $1 \mathrm{~h}$ of annealing at room temperature, the sample was trimmed and then placed into the DAT cooling bath at $-12^{\circ} \mathrm{C}$ for $15 \mathrm{~min}$. After that each specimen was removed from the bath for demolding and removing the bottom tray as well as the metal shim; specimens were then placed back into the cooling bath for $45 \mathrm{~min}$ before testing.

The same procedure was done for experiments under wet condition for which each specimen after demolding was placed into water bath at $26^{\circ} \mathrm{C}$ for $22 \mathrm{~h}$ before placing it into the cooling bath in preparation for running the adhesion measurements.

\section{Sessile Drop Methods and Contact Angle}

Sessile Drop test is the analysis of a drop of target liquid on a solid substrate. The components of sessile drop equipment are a light source, sample stage, lens and image capturing tools. Contact angle can be measured directly by examining the angle formed between the solid and the tangent to the drop surface (Fig. 2). The contact angle is defined as the angle between the tangent to the liquid-fluid interface and the tangent to the liquidsolid interface (Marmur, 2014). It has been reported that a contact angle less than $90^{\circ} \mathrm{C}$ indicates that wetting of the surface is favorable so the liquid will spread over a large surface area; while a contact angle greater than $90^{\circ} \mathrm{C}$ indicates that wetting of the surface is unfavorable so the liquid will minimize its contact angle with the surface (Lee, 2013). So a smaller contact angle indicates that the bond between the substrate and the liquid is most likely not to fail in adhesion; and a bigger contact angle indicates the likelihood of the bond between the substrate and liquid to fail in adhesion. The instrument used to determine the contact angle was the First Ten Ångstroms (FTA-1000 model) designed by Dr. Roger Woodward. That machine operates by taking image of a drop on a camera and analyzing the captured image on a personal computer. The sessile drop method was used in this study to measure the contact angle between water and sealant. Moreover, the calculation of the contact angle was done by using the Young-Laplace equation (Lee, 2013):

$$
\gamma_{l v}(\cos \theta Y)=\gamma_{s v}-\gamma_{s l}
$$

Where:

$\gamma_{l v}=$ Liquid-vapor interfacial tension

$\gamma_{s v}=$ Solid-vapor interfacial tension

$\gamma_{s l}=$ Solid-liquid interfacial tension $\theta Y=$ Young's contact angle

Figure 2 shows an image of the FTA instrument and an image of the sessile drop, respectively. Prior to testing the contact angle with sealant, water and sealant surface was heated in the environmental chamber at different temperature ranging from 40 to $80^{\circ} \mathrm{C}$. Those temperatures represent pavement surface temperature at hot summer season. The solid surface, in this case the sealant, was prepared by melting the sealant in the oven at $185^{\circ} \mathrm{C}$ for $30 \mathrm{~min}$, then slowly pouring into aluminum molds to form a flat and smooth surface. The aluminum molds were cooled down at room temperature for one hour and then placed on the FTA-1000 tray. Water at different temperature was inserted into the syringe and placed inside the FTA-1000 chamber so the temperature could remain constant during measurements; then finally the contact angles of six droplets were evaluated for each water droplets at three sealant surfaces. 


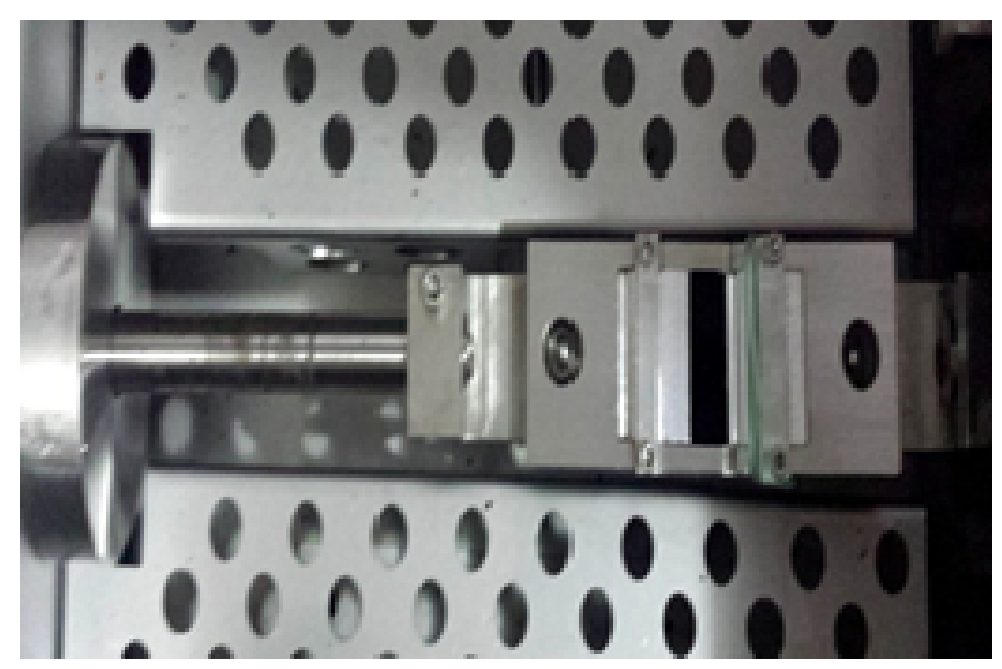

Fig. 1. Schematic of direct adhesion test fixture
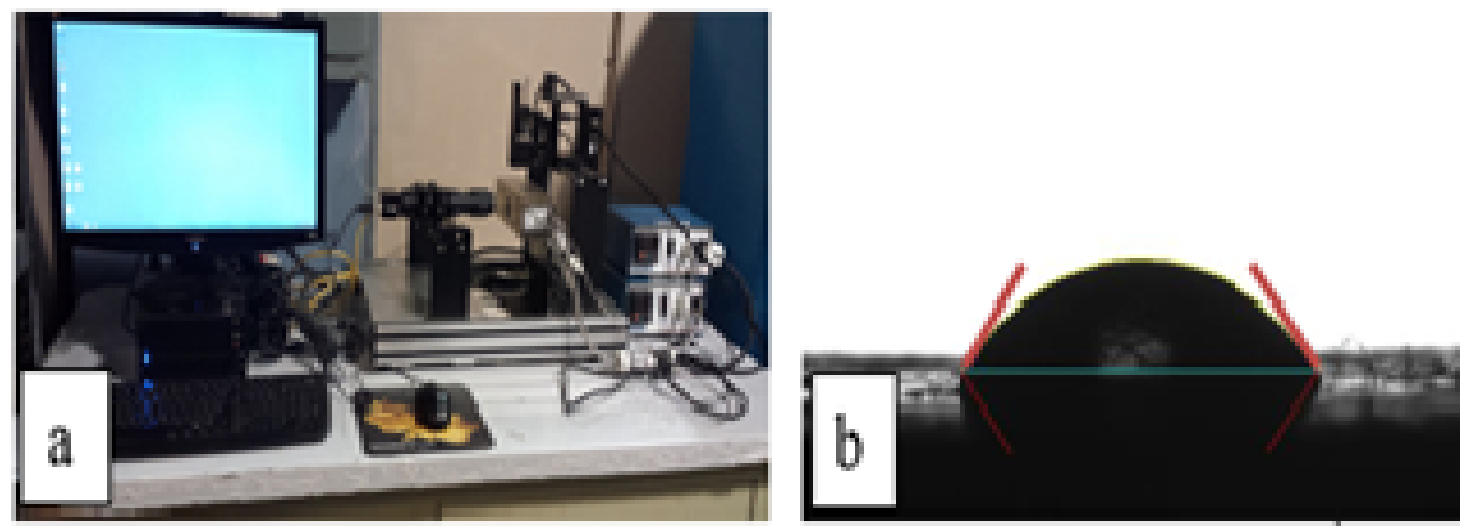

Fig. 2. (a) FTA-1000 and (b) image of a droplet of water on sealant surface

Table 1. Crack sealants and properties

\begin{tabular}{llllllll}
\hline Sealant & $\begin{array}{l}\text { Application } \\
\text { temp. }\left({ }^{\circ} \mathrm{C}\right)\end{array}$ & $\begin{array}{l}\text { Maximum } \\
\text { temp. }\left({ }^{\circ} \mathrm{C}\right)\end{array}$ & $\begin{array}{l}\text { Application } \\
\text { climate }\end{array}$ & $\begin{array}{l}\text { Viscosity at } \\
190^{\circ} \mathrm{C}(\mathrm{Pa} . \mathrm{S})\end{array}$ & $\begin{array}{l}\text { Flow } \\
\text { at } 60^{\circ} \mathrm{C}\end{array}$ & $\begin{array}{l}\text { Resilie } \\
\text { nce, } \%\end{array}$ & $\begin{array}{l}\text { Cone penetration } \\
\text { at } 25^{\circ} \mathrm{C}\end{array}$ \\
\hline Sealant B & 185 & 200 & Moderate climate & 3483 & $3.0 \mathrm{max}$ & $60 \mathrm{~min}$ & $90 \mathrm{max}$ \\
Sealant A & 193 & 204 & Warm to hot climates & 4783 & $5.0 \max$ & $\begin{array}{l}\text { N/A } \\
90 \max \end{array}$ \\
Sealant C & 177 & 204 & Cols to very cold climates & 1354 & $3.0 \mathrm{max}$ & $60 \mathrm{~min}$ & $90-150$ \\
\hline
\end{tabular}

\section{Crack Sealant}

The crack sealants used in this study were hot poured sealants. The sealant B, sealant A and sealant C were the three types of sealants used for the experiment provided by CRAFCO Inc $6975 \mathrm{~W}$. crafco Way, Chandler, AZ 85226 (http://www.crafco.com). Sealant B is a hotapplied asphalt based product from CRAFCO. It is a combination of two different crack sealants and they are commonly used for low and high temperature weather between the joints mainly because it remains ductile for a large temperature range. Table 1 shows crack sealant types and properties based on ASTM D
6690. Sealant A is mainly used in parking lot pavement, highway, street and airfield (Crafco, 2008). Sealant $\mathrm{C}$ is also asphalt based product which is mainly used to seal cracks and joints in cold to very cold climates due to its softness (Crafco, 2008).

\section{Data Analysis}

Adhesion strength of each sealant before and after water conditioning was measured using ADT test which measured load and displacement as a function of time; collected data were then analyzed to determine the fracture energy and peak load as indicators of adhesion 
strength between the sealant and the substrate (Fig. 3). As it can be seen there is a little resistance to de-bonding where the energy starts to be dissipating creating a failure path (Fig. 3). Using the load and displacement data collected during the test, the area under the curve was calculated and divided by the contact surface (area of interface) to find the energy required to break the bond between sealant and substrate (Fig. 4 and 5).

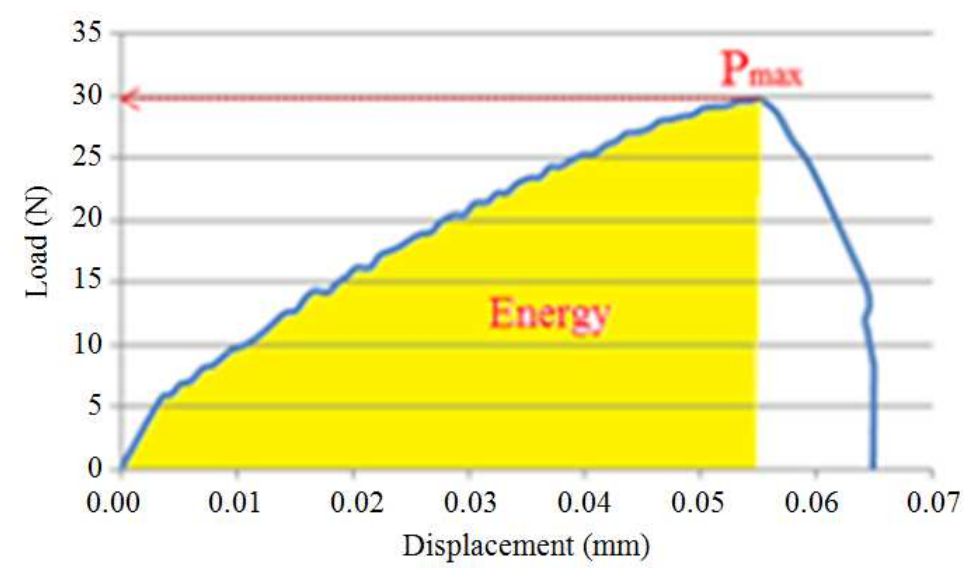

Fig. 3. Maximum load and area under the load-displacement curve

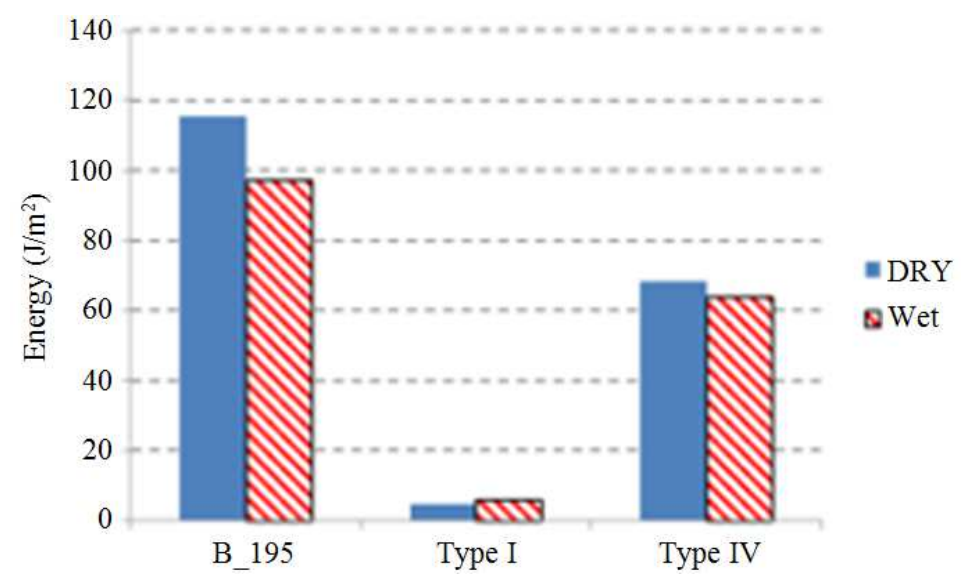

Fig. 4. Energy required to break bond between sealants and aluminum

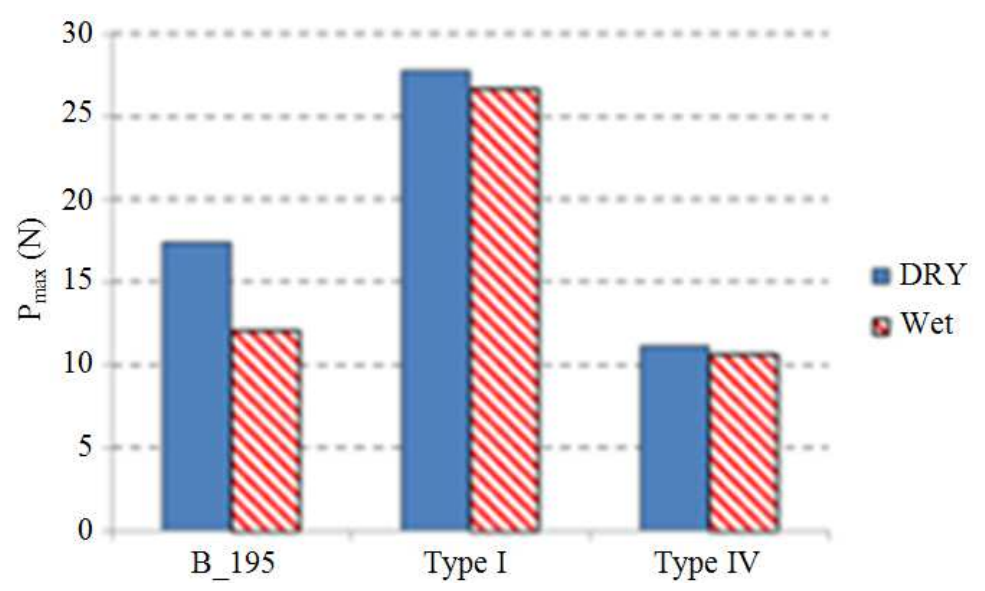

Fig. 5. Load required to break the bond between sealant and the aluminum 
As it can be seen in Fig. 4, there was a significant reduction in both energy and peak load after sealant was exposed to water for $22 \mathrm{~h}$. Accordingly, it can be observed that as the sealant is exposed to water, there is a loss of energy and a reduction of maximum load required to break the bond indicating progressive alteration of sealant surface properties. The loss of energy between the substrate and sealant is due to water affecting the bond between those two by causing a change in surface properties. This in turn could lead to loss of adhesion leading to premature sealant failure. Further researches on the sealant's surface chemistry interaction with water molecules should be conducted. The results also showed that the reduction in adhesion strength due to water exposure varied depending on sealant type; accordingly, sealant A showed marginal change in energy and peak load followed by sealant C. However, sealant B showed a significant loss of energy after conditioning. This can be attributed to the change of surface structure due to water exposure. In addition, the substrate used for the study was an aluminum, which has no porosity; compared to a substrate with rough surface that promotes interlocking and enhance bonding. Furthermore, sealant $\mathrm{C}$ crack sealant also displayed a small amount of energy loss and after conditioning.

Accordingly, based on the results of direct adhesion test, three sealants were ranked according to their water susceptibility with sealant B being the most water susceptible with $15.8 \%$ reduction in energy after water conditioning. This was followed by sealant $C$ with $6.4 \%$ reduction in energy. This was when sealant A deemed to be the least susceptible to water with minor changes in adhesion strength.

\section{Discussion}

The trend was almost the same with respect to peak load with the sealant $\mathrm{B}$ showing a drastic reduction peak load $(30.9 \%)$ followed by sealant C $(4.2 \%)$ and sealant A (4.0\%); this further confirms that sealants vary in term of their susceptibility to water and that sealant surface properties changes when exposed to water for extended period of time.

To further study the effect of water on surface properties of sealant, contact angles between droplet of water and surface of each sealant was measured using a sessile drop method. Contact angle was used as a measure of sealant water phobicity and its surface interaction with water molecules. Furthermore, the effect of temperature on the contact angle was studied by conducting the experiment at temperatures ranging from 40 to $80^{\circ} \mathrm{C}$ representing pavement surface temperature in hot summer season. The latter test was conducted with the aid of an environmental chamber capable of sealing both pendent drop and the substrate surface equipped with temperature control system synchronized with the test equipment (Fig. 2). It was observed that as the temperature increases so does the contact angle (Fig. 6). However, the change in the contact angle varied among sealants with sealant A crack sealant being the least affected by the temperature. This was when water made the smallest contact angle with sealant A crack sealant indicating this sealant may have a good wettability with water. This was when both sealant C and B not only showed a large contact angle; but also a large temperature dependence showing a significant change in their contact angle with the increase of temperature. The observed variation of the contact angle could be attributed to the changes in surface properties.

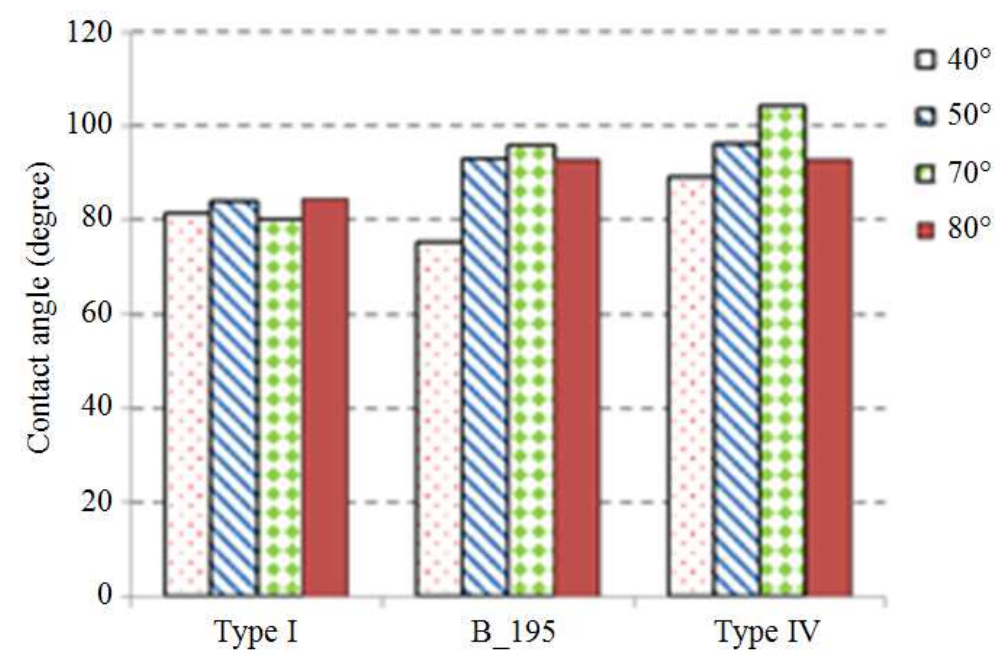

Fig. 6. Contact angle between water and dry sealant at various surface temperatures 


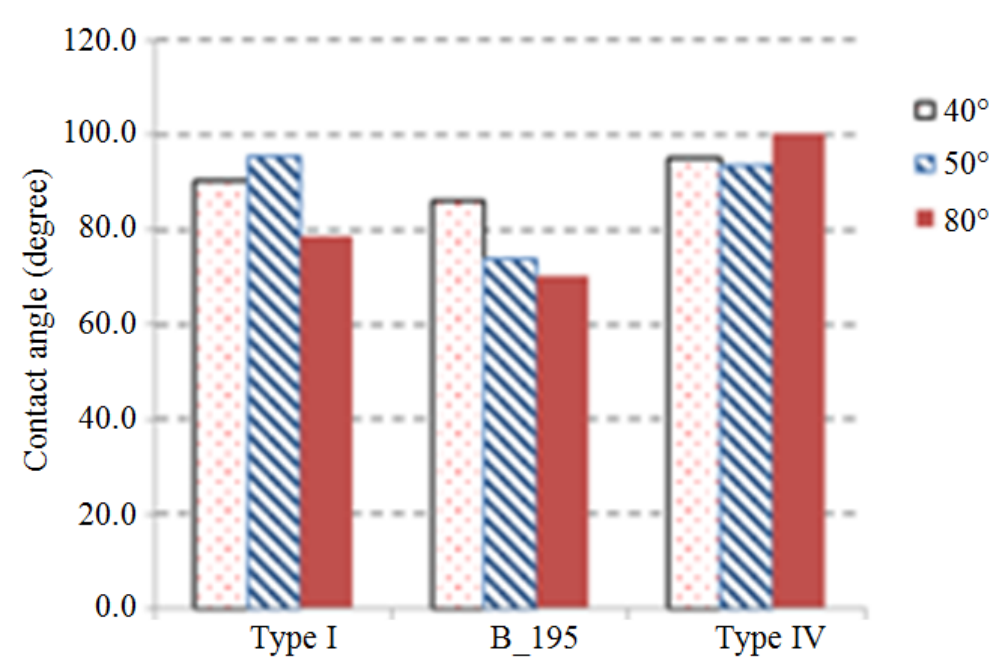

Fig. 7. Contact angle between conditioned sealant and water at various surface temperatures

Furthermore, to study interaction of water droplet with conditioned sealants, contact angles between water conditioned sealants and water was measured using a sessile drop method. To condition the sealants, each specimen was pour into an aluminum mold and was placed into water at $85^{\circ} \mathrm{C}$ for one hour. The aluminum mold was completely submerged into water and the temperature was kept constant. Analysis of the contact angle results showed that sealant contact angle varied significantly after conditioning (Fig. 7). The sealant B revealed a decrease in contact angle after conditioning and its contact angle decreased as the temperature increased. However, both sealant A and sealant $\mathrm{C}$ crack sealants showed an increase in their contact angle after water conditioning indicating significant change in surface properties after water condition.

\section{Conclusion}

Sealants are commonly used to insulate cracks and joints; however extended exposure of sealants to water can negatively impact sealants properties causing gradual degradation of its performance. However, sealants shows different degradation rate when exposed to water; this paper investigates the change in sealant's adhesion strength and surface properties before and after water conditioning. To study adhesion strength and its change due to water conditioning, three different types of sealant were tested using Direct Adhesion Tester (DAT). The experiment was done by pouring the crack sealant into a two-piece aluminum mold and placing the molded specimen in water for conditioning. The direct adhesion test was conducted by moving two aluminum end pieces at a constant rate. The displacement and load was recorded as a function of time to determine a maximum load (Pmax) and the fracture energy required to break the bond.
The tests were performed on three different sealants before and after water conditioning; it was shown that both energy and peak load reduced as a result of water conditioning. However, the level of reduction varied among sealants. To further study each sealant's water phobicity as well as the effect of water exposure on changing sealant surface properties, contact angles between a droplet of water and sealant surface was measured at different temperatures. The study results showed that sealant B has the highest contact and the highest sensitivity to temperature variation. This was also in agreement with the direct adhesion test results indicating the highest drop in energy and peak load as a result of water conditioning. This in turn indicates that sealant $\mathrm{B}$ is most susceptible to water; this was followed by sealant $\mathrm{C}$ while the sealant $\mathrm{A}$ was found to be least susceptible to water.

\section{Acknowledgment}

This research is sponsored by the Center for Highway Pavement Preservation, a University Transportation Center funded by U.S. Department of Transportation's Office of the Assistant Secretary for Research and Technology. The authors would like to acknowledge valuable assistance of Daniel Oldham and Farrokh Mirzaefard with laboratory experiments and data analysis. The contents of this paper reflect the view of the authors, who are responsible for the facts and the accuracy of the data presented herein. This paper does not constitute a standard, specification, or regulation.

\section{Funding Information}

The work reported here was financially supported by the Center for Highway Pavement Preservation, a 
University Transportation Center funded by U.S. Department of Transportation's Office of the Assistant Secretary for Research and Technology.

\section{Author's Contributions}

Ahmed Lamarre: Participated in all experimental testing, data-analysis and contributed to the writing of the manuscript.

Elham H. Fini: Participated in experimental plan and testing, data-analysis and contributed to the writing of the manuscript.

Taher M. Abu-Lebdeh: Participated in experimental plan, data-analysis and contributed to the writing of the manuscript.

\section{Ethics}

The authors would like to disclose that Dr. Taher M. Abu-Lebdeh (Co-author) is a member of the editorial board for the American Journal of Engineering and Applied Sciences.

\section{Reference}

Allen, J.S., 2003. An analytical solution for determination of small contact angles from sessile drops of arbitrary size. J. Colloid Interface Sci., 261: 481-489. DOI: 10.1016/S0021-9797(03)00127-9

Al-Qadi, I.L. and E. Fini, 2010. Development of the crack sealant adhesion test. ASTM J. Test. Evalut.

Al-Qadi, I.L., S.H. Yang, E. Fini. J.F. Masson and K. McGhee, 2009. Performance-based specification guidelines for the selection of bituminous-based hotpoured crack sealants. J. Assoc. Asphalt Pav. Technol., 78: 491-534.

Angela, R., P. Lee-Sullivan and T. Bremner, 2009. Selecting concrete pavement joint sealants. II: Case study. J. Mater. Civil Eng., 11: 309-316. DOI: 10.1061/(ASCE)0899-1561(1999)11:4(309)

ASTM D6690, 2001. Standard specification for joint and crack sealants, hot applied, for concrete and asphalt pavements. Standard ASTM D6690.

Bert, S., 2011. How moisture affects adhesives, sealants and coating. Adhesion and Bonding.

Biel, T. and H. Lee, 1997. Performance study of portland cement concrete pavement joint sealants. J. Transport. Eng., 123: 398-404. DOI: 10.1061/(ASCE)0733-947X(1997)123:5(398)

Crafco, 2008. Product data sheet.

Fini, E. and I.L. Al-Qadi, 2011. Development of a pressurized blister test for interface characterization of aggregate highly polymerized bituminous materials. ASCE J. Mater. Civil Eng., 23: 656-663. DOI: 10.1061/(ASCE)MT.1943-5533.0000222
Fini, E., I.L. Al-Qadi and S.H. Dessouky, 2006. Adhesion of hot-poured crack sealant to aggregate. Proceedings of the 85th Transportation Research Board Annual Meeting, (BAM' 06), Washington, DC.

Gail, K., 2003. Specifying joint sealants for concrete repair. Concrete Repair Bulletin.

Haithem, S., A. Shalaby and L. Kavanagh, 2008. Performance evaluation of joint and crack sealants in cold climates using DSR and BBR tests. J. Mater. Civil Eng., 20: 470-477.

DOI: 10.1061/(ASCE)0899-1561(2008)20:7(470)

Lanteri, P.C., 2003. Sealant joint rehabilitation. J. Architectural Technol., 21: 2-8.

Lee, Y.Y., 2013. Contact angle and wetting properties.

Li, Q., R. Crowley, D. Bloomquist and R. Roque, 2014. Newly developed adhesive strength test for measuring the strength of sealant between joints of concrete pavement. Am. Society Civil Eng., 26: 1-8. DOI: 10.1061/(ASCE)MT.1943-5533.0001020

Marmur, A., 2014. Soft contact: Measurement and.

Masson, J.F. and M.A. Lacasse, 1999. Effect of hot-air lance on crack sealant adhesion. J. Transport. Eng., 125: 357-363.

DOI: 10.1061/(ASCE)0733-947X(1999)125:4(357)

Masson, J.F., C. Lauzier, P. Collins and M.A. Lacasse, 1998. Sealant degradation during crack sealing of pavements. J. Mater. Civil Eng., 10 250-255. DOI: 10.1061/(ASCE)0899-1561(1998)10:4(250)

Panek, J.R., 1963. Causes of joint sealant failures.

Petrie, E., 2005. Modes of sealant failure. SpecialChem.

Petrie, E.M., 2006. How sealants function. Adhesives and Sealants Industry.

Pozrikidis, A.H., 2013. Deformation of an elastic substrate due to a sessile drop. Eur. J. Mechan. B/Fluids, 43: 90-99. DOI: 10.1016/j.euromechflu.2013.07.005

Ramesh, M., R. Matu, T. Montgomery and B. Smita, 2011. Temperature aging, compression recovery, creep and weathering of a foam silicone sealant for bridge expansion joints. J. Mater. Civil Eng., 23: 287-297. DOI: 10.1061/(ASCE)MT.1943-5533.0000166

Warseck, K., 2003. Why sealants fail.

White, C.C., K.T. Tan, E.P. O'Brien, D.L. Hunston and J.W. Chin et al., 2011. Design, fabrication and implementation of thermally driven outdoor testing devices for building joint sealants. 82: 025112-025112. DOI: $10.1063 / 1.3543817$

Yetkin, Y., A. Qatan and J. Prozzi, 2006. Field manual for crack sealing.

Yun, T., O. Lee, S.W. Lee, I.T. Kim and Y.H. Cho, 2010. A performance evaluation method of preformed joint sealant: Slip-down failure. Constr. Build. Mater., 1677-1684. DOI: 10.1016/j.conbuildmat.2010.10.015 